\title{
Carbon Trading and the Morality of Markets in Laudato Si
}

\author{
Eduardo M. Peñalver ${ }^{1}$
}

\section{Introduction}

In a brief but much noted passage of Laudato Si, Pope Francis criticized so-called "cap and trade" approaches to reducing carbon emissions. "The strategy of buying and selling 'carbon credits,'” he said, "can lead to a new form of speculation, which would not help reduce the emission of polluting gases worldwide." 2 Commentators have interpreted the passage as a categorical and moralistic rejection of marketbased solutions to climate change. Read within the context of the encyclical and the broader Catholic social tradition, however, it becomes clear that the Pope's critique of cap-and-trade is simultaneously more and less all-encompassing than these initial readings allow.

The Pope's objection to market-based approaches to controlling carbon emissions is closely tied to his analysis of global economic inequality. It reflects an astute appreciation of the way in which inequality can distort the market's ability to serve as an efficient and just means of allocating the costs of environmental protection. His critique therefore echoes earlier discussions within liberation theology of the notion of "structural sin" and reinforces calls within Catholic Social Thought for analysis of markets always to be considered within - and at the service of - a broader moral framework. Situating Francis's discussion within these traditions makes clear that, under the right circumstances, a cap and trade system of emissions regulation could be consistent with the Pope's analysis in Laudato Si.

In this short essay, I will briefly describe the so-called "market-based" approaches to greenhouse gas reduction that have dominated policy discussions of climate change in recent years. I will then situate Pope Francis's objection to these sorts of policy responses, both within the broader climate debate and within the tradition of Catholic social teaching. Finally, I will propose constraints that would seem to address Pope Francis's concerns.

\section{A Brief Overview of Market-Based Climate Policies}

Climate change presents a slow-motion environmental catastrophe that is unique in both its scale and its apparent intractability. Its causes and effects operate on a global scale over an extended period of time. Both of these features contribute to the difficulty of addressing it. The longevity of greenhouse gasses in the atmosphere and lags in their impact on climate mean that reductions in emissions

\footnotetext{
${ }^{1}$ Allan R. Tessler Dean and Professor of Law, Cornell Law School. I am grateful to Kristen Ferries and Hae Jin Kang for superb research assistance.

2 Laudato Si, No. 171.
} 
do not generate meaningful consequences for the climate for decades. ${ }^{3}$ These long time lags test the far-sightedness of our existing political processes. Moreover, carbon emissions anywhere in the world will contribute to climate change across the planet. And so any action taken to combat climate change must necessarily be global in its reach. Individuals (or even individual countries) - no matter how virtuously they behave - simply cannot solve the problem on their own.

But perhaps the most daunting feature of climate change is that carbon emissions go to the very core of the modern industrial economy. For at least two centuries, our civilization has been built on the energy derived from fossil fuels. ${ }^{4}$ Unlike, say, chlorofluorocarbons, whose impact on the ozone raised similar challenges of global scale and long-term impact and yet whose emissions were successfully curtailed by the international community, ${ }^{5}$ it is likely that reducing carbon emissions will require fundamental changes to the organization of our systems of production and consumption. Virtually every activity that modern human beings undertake involves the creation of carbon emission. ${ }^{6}$ The food we eat is grown using production methods that emit carbon; ${ }^{7}$ it is transported to us from around the world in carbon emitting vehicles; ${ }^{8}$ it is packaged in materials produced

3 B. Ewing and D. A. Kysar, "Prods and pleas: limited government in an era of unlimited harm," Yale L.J., 121 (2011), p. 369 ("[M]any of the most devastating impacts of climate change will not happen for decades or centuries hence, even though actions taken today critically affect whether they will occur."). R.N. Stavins, "A meaningful U.S. cap-and-trade system to address climate change," Harv. Envtl. L. Rev., 32 (2008), p. 306 (noting that the long-term nature of the climate problem "offers significant temporal flexibility regarding emission reductions" and advocating for policies that take advantage of that temporal flexibility by "setting annual emission targets that gradually increase in stringency").

${ }^{4}$ See J. Rifkin, The Hydrogen Economy, (Penguin, 2003) p. 64 ("Remove fossil fuels from the human equation and modern industrial civilization would cease to exist.").

5 O. E. Nangle, "Stratospheric ozone: United States regulation of chlorofluorocarbons," B.C. Envtl. Aff. L. Rev., 16 (1989), p. 536-555 (explaining how chlorofluorocarbons remain in the atmosphere despite natural atmospheric cleansing for up to 120 years and crediting the Clean Air Act, the United Nations Environmental Program, and the Montreal Protocol as the first moves toward addressing the problem).

${ }^{6}$ Ewing and Kysar, Prods and pleas, p. 369 (noting that "all human beings and enterprises contribute - however marginally - to the phenomenon of anthropogenic climate change" and arguing that robust tort law provides an alternative to government overreach in climate change policy).

${ }^{7}$ Agricultural activities, such as the cultivation of crops and livestock for food, contribute almost $10 \%$ of all carbon emissions in the United States. See Environmental Protection Agency, Sources of Greenhouse Gas Emissions (Nov. 6, 2016, 11:14 AM), (https://www.epa.gov/ghgemissions/sources-greenhouse-gas-emissions\#agriculture) (citing livestock, especially cattle, and rice production as significant contributors to carbon emissions); see also R. S. Avi-Yonah and D. M. Uhlmann, "Combating global climate change: why a carbon tax is a better response to global warming than cap and trade," Stan. Envtl. L.J., 28 (2009), p. 12 (discussing how the developing world will struggle to adapt to climate change as water and food supplies become increasingly scarce).

8 See Rifkin, Hydrogen Economy, p. 64. 
through methods that emit carbon; ${ }^{9}$ we drive to the grocery store (or ride a bus or take a subway) in vehicles that either emit carbon or rely on power generation methods that do; we then take it home to a dwelling that is heated or cooled through methods that emit carbon; and cook the food on a stove that does the same. ${ }^{10}$ In thinking about a carbon neutral future, it is not clear how we get from here to there without dramatic changes in virtually every corner of our lives.

Over the past few decades a broad policy consensus has emerged around the desirability of flexible approaches to implementing greenhouse gas reductions. The complexity and ubiquity of behaviors that result in carbon emissions means that attacking the problem at the ultimate moment that the carbon is emitted into the atmosphere would necessarily be highly intrusive, inefficient and expensive. ${ }^{11}$ The most promising and comprehensive approaches to carbon emissions reductions focus on interventions far upstream in the carbon economy. Regulating upstream e.g., when fossil fuels are extracted from the ground or converted into a usable form - leaves to the marketplace the allocation of carbon emissions to their most valuable uses. ${ }^{12}$

Two tools in particular have attracted broad support among climate change policy scholars - so-called "cap and trade" and a carbon tax. ${ }^{13}$ Under a cap and trade approach, total carbon emissions would be capped at some fixed amount. ${ }^{14}$ Entities wishing to engage in specified carbon-emitting activities would then need to obtain a permit entitling them to do so. How they procured the permit would depend on the method for initially allocating the permits under the scheme. Under some

\footnotetext{
${ }^{9}$ Ibid.

10 Ibid.

${ }^{11}$ Regulations that attempt to combat carbon emissions at the source are often referred to as "command and control" regulations. See A. Carlin, "Global climate change control: is there a better strategy than reducing greenhouse gas emissions?," U. Pa. L. Rev., 155 (2007), p. 1475. Although command and control programs are relatively inexpensive to administer, they are significantly costlier to consumers than market-based alternatives. See J. B.

Wiener, "Global environmental regulation: instrument choice in legal context," Yale L.J., 108 (1999), p. 719 (estimating command and control's disadvantage in abatement costeffectiveness at $\$ 1$ trillion in the global climate context).

12 See Avi-Yonah and Uhlmann, "Combating global climate change," p. 31 (discussing how upstream regulations (those that focus on fossil fuel production) "have the greatest ability to ensure that all sources of carbon dioxide emissions are affected, because [they focus] on carbon at the point that it enters the economy.").

13 See Stavins, "A meaningful U.S. cap-and-trade system," p. 305 (describing cap-and-trade as "scientifically sound, economically rational, and politically feasible"); see also Avi-Yonah and Uhlmann, "Combating global climate change" (advocating for a carbon tax policy because it is simple, cost-certain, produces revenue, and provides a signaling mechanism to producers and consumers).

14 See Stavins, "A meaningful U.S. cap-and-trade system,” p. 298. ("A cap-and-trade system limits the aggregate emissions of a group of regulated sources by creating a limited number of tradable emission allowances and requiring each firm to surrender a quantity of allowances equal to its own emissions.").
} 
approaches, they might be able to acquire permits at a government auction; under others, the government would simply give a fixed number of permits to certain emitters. ${ }^{15}$ Once the permits were allocated, however, the "trade" element would kick in. Entities that would rather purchase a permit and emit than cut their emissions would acquire permits from existing permit-holders - those who would rather sell their permit and reduce their emissions. ${ }^{16}$ The ability to trade permits ensures that emitters who can more cheaply reduce their emissions will do so while those for whom it is more costly to reduce emissions will pay for the permits. ${ }^{17}$ The result is that emissions reductions are accomplished for as low a cost as possible.

Carbon taxes are similar to cap and trade in their flexibility, but they do not set a fixed amount of permissible carbon emissions. Instead, they impose an across-theboard tax on carbon that makes it more expensive to emit. 18 Those for whom reducing emissions is cheaper than paying the tax will do so. Those for whom paying the tax is cheaper will continue to emit. ${ }^{19}$ By manipulating the level of the tax, governments can increase the cost of emitting carbon to achieve emissions reduction targets while ensuring that the burdens of reducing emissions fall on those for whom doing so is least costly.

Three features of these market-based approaches are particularly relevant to Pope Francis's evaluation of them. First, they tend to make activities that involve the emission of carbon more expensive than they would be absent the schemes. ${ }^{20}$ The mechanisms through which this occurs varies between the two approaches. Under cap and trade, costs increase because emitters must incur the expense of installing less carbon-intensive technology or purchasing carbon permits. Under a carbon tax, the cost of emitting is increased- again - by the need to either install

15 Ibid. ("The government may initially distribute allowances for free or sell them through an auction.").

16 See Ibid. ("Firms' ability to trade emission allowances creates a market in which allowances migrate toward their highest-valued use").

17 See Ibid.

18 See Avi-Yonah and Uhlmann, "Combating global climate change," p. 32 ("A carbon tax would be imposed on all oil, coal, and natural gas production in the United States, as well as all imports.").

${ }^{19}$ See also M. Waggoner, "Why and how to carbon tax," Colo. J. Int'l Envtl. L. \& Pol'y, 20 (2008), p. 6 ("Individuals can change their conduct to reduce their carbon tax liability. Although some users of certain carbon products, such as gasoline, may have little ability to reduce their carbon-based purchases, other users may be flexible even in the short run, and even more users should be flexible in the long run.") (advocating for a revenue-neutral carbon tax to replace or subsidize other emissions control systems such as subsidies, command-and-control regulations, and cap-and-trade).

20 See Avi-Yonah and Uhlmann, "Combating global climate change," p. 30 ("A central feature of the market-based approaches, therefore, is developing a price signal for carbon that incorporates the costs of that externality and drives the market toward finding acceptable alternatives."); see also Stavins, "A meaningful U.S. cap-and-trade system," p. 334 ("the anticipated price increases will take place gradually over much longer periods of time than did recent spikes in energy prices."). 
new technology or pay the tax. The extent to which these costs can be passed on to downstream consumers in the form of higher prices depends on the context, such as the availability of less carbon-intensive substitutes for the product or activity in question. ${ }^{21}$ The ubiquity of carbon emissions in the modern industrial economy suggests that both cap and trade and carbon taxes would translate into broadly increased prices for consumers for everything from food to fuel to consumer products. $^{22}$

Second, in light of the currently unequal distribution of wealth and income, the bite of these increased prices would be felt acutely by those with the least purchasing power. There is little reason to think that products consumed by the wealthy would increase in price any more rapidly than those consumed by the poor. Rather, the safest assumption is that prices would increase across the board for rich and poor alike. ${ }^{23}$ But, because the poor spend a greater portion of their income on consumption of goods, price increases would be more onerous for the poor than for the well-off. ${ }^{24}$

Third, and cutting in the other direction, both carbon taxes and (depending on the details) a cap and trade scheme have the potential to generate significant financial resources for the state. Because the state would have the power to determine how to use those resources, the state would also have some control over the distributive consequences of both cap and trade and carbon taxes.

${ }^{21}$ R. S. Pindyck \& D. L. Rubinfeld, Microeconomics, 8th edn. (Prentice Hall, 2013), pp. 33-35 (discussing the elasticity of demand, defined as the percentage change in the quantity demanded resulting from a percentage increase in price). See also Sperling and Yeh, "Low carbon fuel standards," Issues in Science and Technology, 25.1, (2009) p. 57 (describing how a carbon tax would work well in the electricity sector, where "suppliers can choose among a wide variety of commercially available low-carbon energy sources, such as nuclear power, wind energy, natural gas, or even coal with carbon capture and sequestration," but doubting its effectiveness in the transportation sector, where oil producers "have become almost completely dependent on petroleum ... and can't easily or quickly find or develop lowcarbon alternatives"); S. Sewalk, "A carbon tax with reinvestment is WTO compatible," Fordham Envtl. L. Rev., 25 (2014), p. 377 ("Another advantage is that the tax would encourage companies to continue to invest in new technologies... [T] he carbon tax also incentivizes consumers to request and purchase lower emission products so the tax liability passed on to them is reduced.").

22 See T. M. Roberts, "Mitigating the distributional impacts of climate change policy," Wash. \& Lee L. Rev., 67 (2010), p. 209 (discussing how either a cap-and-trade or carbon tax system would increase the cost of gasoline, electricity, home heating fuels, and all goods manufactured or distributed using fossil fuels).

${ }^{23}$ See Ibid.

24 See S. E. Gaines and R. A. Westin, Introduction, in Taxation for Environmental Protection, (Greenwood Publishing Group, 1991), p. 11 ("The regressive effect of consumption-based taxes is well known. Because poor people spend a higher proportion of their income on consumption of goods than do the wealthy (who usually devote some of their income to savings or non-consumptive expenditures), consumption-based taxes affect the poor disproportionately."). 


\section{Situating Pope Francis's Views on Markets Within the Catholic Social Tradition}

\section{A. Catholic Teaching on Markets Before Francis}

Since the advent of modern Catholic Social Teaching with the publication of Rerum Novarum in 1890, the magisterium has woven a delicate balance between affirming the importance of private property and economic freedom to human dignity, on the one hand, and, on the other, asserting the necessary subservience of property rights and markets to collective regulation based on sound moral analysis of economic transactions. Although often described as a kind of third path between socialism and capitalism, the Catholic critique of the dominant economic ideologies of the twentieth century was always marked by an asymmetry. This asymmetry derived from the Popes' repeated emphasis on the importance of the institution of private ownership (including private ownership of economically productive property) to human beings' ability to flourish.

This Catholic commitment to the importance of private property led the magisterium to condemn communism in a very categorical way. Because communists reject private ownership of the means of production, the Church argued, communist economic systems are always unjust. Pope Leo XIII set the stage for this analysis when he concluded in Rerum Novarum that "the main tenet of socialism, community of goods, must be utterly rejected, since it only injures those whom it would seem meant to benefit, is directly contrary to the natural rights of mankind, and would introduce confusion and disorder into the commonweal. The first and most fundamental principle, therefore, if one would undertake to alleviate the condition of the masses, must be the inviolability of private property." 25

In contrast, Catholic Social Teaching has viewed the flaws of capitalism as somewhat more contingent. If capitalism is an economic system built around private ownership and the market economy, then it is not in its essential nature opposed to justice in the same way that communism is. Rather than condemning capitalist production in the same stark terms he used against communists, Pope Leo XIII limited himself to admonishing business owners to exercise their authority justly:

The following duties bind the wealthy owner and the employer: not to look upon their work people as their bondsmen, but to respect in every man his dignity as a person ennobled by Christian character. They are reminded that, according to natural reason and Christian philosophy, working for gain is creditable, not shameful, to a man, since it enables him to earn an honorable livelihood; but to misuse men as though they were things in the pursuit of gain, or to value them solely for their physical powers - that is truly shameful and inhuman. ${ }^{26}$

25 Rerum Novarum, No. 15.

26 Ibid., at No. 20. 
In the years since Rerum Novarum, Catholic Social Teaching has always taken pains to criticize certain recurring - perhaps even pervasive - features of capitalist economic life. The encyclicals enjoin excessively low wages, ${ }^{27}$ long working hours, ${ }^{28}$ suppression of workers' rights to organize, ${ }^{29}$ consumerism, ${ }^{30}$ and the like. Catholic teaching has described these aspects of capitalism, however, as accidental, not as part of its essential moral quality. But these shortcomings have been sufficiently widespread that Catholic teaching was able to credibly position itself as not wholly aligned with any economic system, even as its critique of communism was always far more categorical and uncompromising.

The fall of the Soviet bloc presented a challenge to this basic orientation for Catholic Social Teaching as a third way between two flawed poles. It has taken some time for the Church to find its voice in a unipolar world. For example, in Centessiumus Annus, the first social encyclical published after the fall of the Berlin Wall, John Paul II continued to treat communism as an unmitigated moral evil while describing capitalism as a system whose injustice is entirely contingent on circumstance. He put it as follows:

[C]an it perhaps be said that, after the failure of Communism, capitalism is the victorious social system, and that capitalism should be the goal of the countries now making efforts to rebuild their economy and society? Is this the model which ought to be proposed to the countries of the Third World which are searching for the path to true economic and civil progress?

The answer is obviously complex. If by "capitalism" is meant an economic system which recognizes the fundamental and positive role of business, the market, private property and the resulting responsibility for the means of production, as well as free human creativity in the economic sector, then the answer is certainly in the affirmative, even though it would perhaps be more appropriate to speak of a "business economy", "market economy" or simply "free economy." 31

In the same encyclical, John Paul II even seemed to tack a bit to the right, perhaps in order to remain on the familiar ground between opponents on the left and the right. With communism largely defunct as a global economic force, he introduced for the first time a new opponent on the left: the "Social Assistance State":

[E]xcesses and abuses, especially in recent years, have provoked very harsh criticisms of the Welfare State, dubbed the "Social Assistance State".

27 Ibid., at Nos. 20, 39; Laborem Exercens, No. 19.

${ }^{28}$ Laborem Exercens, No. 19; Rerum Novarum, Nos. 20, 39.

${ }^{29}$ Laborem Exercens, No. 20.

30 Centesimus Annus, Nos. 36, 41.

31 Centessimus Annus, No . 42. 
Malfunctions and defects in the Social Assistance State are the result of an inadequate understanding of the tasks proper to the State. Here again the principle of subsidiarity must be respected: a community of a higher order should not interfere in the internal life of a community of a lower order, depriving the latter of its functions, but rather should support it in case of need and help to coordinate its activity with the activities of the rest of society, always with a view to the common good.

By intervening directly and depriving society of its responsibility, the Social Assistance State leads to a loss of human energies and an inordinate increase of public agencies, which are dominated more by bureaucratic ways of thinking than by concern for serving their clients, and which are accompanied by an enormous increase in spending. In fact, it would appear that needs are best understood and satisfied by people who are closest to them and who act as neighbours to those in need. ${ }^{32}$

John Paul II did caution that the fall of communism created the danger of a doctrinaire capitalism that put markets above "the service of human freedom" and out of reach of "a strong juridical framework." 33 He warned of the "risk that a radical capitalistic ideology could spread which refuses even to consider these problems, in the a priori belief that any attempt to solve them is doomed to failure, and which blindly entrusts their solution to the free development of market forces." ${ }^{34}$ But he presented this danger as something to look out for, not as an imminent (or existent) threat.

If we were to summarize the basic orientation of Catholic Social Teaching towards markets prior to the arrival of Pope Francis, it would look something like the following: private ownership and markets are not perfect, but (unlike communist economic systems) they are essentially consistent with human freedom and dignity. Markets and market actors must be subordinate to moral and juridical constraints on market activity to ensure that they actually operate in the service of the common good. Dehumanizing poverty (particularly in the developing world) and alienating consumerism (particularly in the developed world) are realities that we must collectively combat, but the solution to those problems lies within a modified market system not terribly unlike the one that prevails in Western Europe.

\section{B. Francis on the Market}

Although it is still relatively early in Francis's papacy, his distinctive perspective on private ownership and markets is beginning to come into focus. His discussions of private property slant far more heavily than previous popes towards admonitions about its potential pitfalls. And his insistence on the subordination of ownership to

\footnotetext{
32 Ibid. at 48.

33 Ibid. at 42.

34 Ibid.
} 
the common good is more prominent than it was for his predecessors. (LS 6, 52, 93) For instance, in Laudato Si, he says:

Whether believers or not, we are agreed today that the earth is essentially a shared inheritance, whose fruits are meant to benefit everyone. For believers, this becomes a question of fidelity to the Creator, since God created the world for everyone. Hence every ecological approach needs to incorporate a social perspective which takes into account the fundamental rights of the poor and the underprivileged. The principle of the subordination of private property to the universal destination of goods, and thus the right of everyone to their use, is a golden rule of social conduct and "the first principle of the whole ethical and social order." (LS 93)

Gone is the defense of the necessity of private property to human well being, which had been de rigueur in prior encyclicals. It is unlikely that this absence is due to a rejection of the importance of private ownership. Instead, this new tone seems more likely to result from Francis's desire to reshape the orientation of Catholic Social Teaching within a contemporary context that is characterized by a consensus around the institution of private property. In the absence of a communist rival, rather than defend what most people already accept, Francis chooses to focus on spelling out what the poor require in order to flourish in addition to private property. Quoting the Paraguayan bishops, Francis says:

Every campesino has a natural right to possess a reasonable allotment of land where he can establish his home, work for subsistence of his family and a secure life. This right must be guaranteed so that its exercise is not illusory but real. That means that apart from the ownership of property, rural people must have access to means of technical education, credit, insurance, and markets. (LS 94)

All of this presupposes the institution of private ownership, but that institution by itself is not enough to ensure justice for the poor. The institution must be accompanied by just distribution and by other institutions, such as an educational system, banking, insurance and fair markets in which campesinos' goods can be sold for a just price.

In addition to this assertion that property by itself is not enough, Francis adds a pointed critique of the excesses of private ownership, which contribute to the miseries of the poor:

In many places, ... productive land is concentrated in the hands of a few owners due to "the progressive disappearance of small producers, who, as a consequence of the loss of the exploited lands, are obliged to withdraw from direct production." The most vulnerable of these become temporary labourers, and many rural workers end up moving to poverty-stricken urban areas. The expansion of these crops has the effect of destroying the complex network of ecosystems, diminishing the diversity of production and affecting regional 
economies, now and in the future. In various countries, we see an expansion of oligopolies for the production of cereals and other products needed for their cultivation. (LS 134)

Complementing Francis's critique of private property is a critique of markets, one that is far more trenchant and thoroughgoing than those leveled by his predecessors. Francis roots his critique in a deep skepticism about the wisdom of markets. At the foundation of that skepticism are two shortcomings that Francis perceives in market arrangements.

The first problem he identifies is the market's tendency to commodify goods that have intrinsic value. This critique comes through particularly strongly in Laudato Si when Francis - using endangered species as his example - notes the gap that opens up between intrinsic and market value when natural resources are traded. "It is not enough," he says, "to think of different species merely as potential 'resources' to be exploited, while overlooking the fact that they have value in themselves." 35 If market exchange does not properly account for the full value of the resources being traded and consumed, then we cannot confidently rely on market exchanges to advance the common good, and the case for more wide-ranging state intervention in economic relations becomes stronger.

The second shortcoming is both an extension of this problem of commodification and an application of it in the human realm. If market transactions are cognizant only of market values, then those transacting in markets will tend to exclude from their consideration the interests of human beings who do not themselves have at their disposal resources that the market values. ${ }^{36}$ Because of this, Francis says, the market generates "an economy of exclusion and inequality" in which "masses of people find themselves excluded and marginalized: without work, without possibilities, without means of escape."37

Earlier Catholic critiques of capitalism have treated the market as a fundamentally just system. On this earlier view, poverty and exclusion are adventitious conditions in need of state attention, but not intrinsic features of market economies. For Francis, however, exclusion and commodification do not exist at the edges of a fundamentally just market economy. Instead, they reflect the dominance within contemporary capitalism of a "throw away' culture" characterized by widening inequality and an "idolatry" of money and free markets:

While the earnings of a minority are growing exponentially, so too is the gap separating the majority from the prosperity enjoyed by those happy few. This

\footnotetext{
35 Laudato Si, No. 33.

${ }^{36}$ See A. Sen, "Social justice and the distribution of income," Handbook of Income

Distribution, 1 (2000), p. 73, 78 (explaining that while markets may be efficient for commodities, they tend to ignore "functionings," defined as the experiences that constitute the quality of life) ("It is certainly true that market prices exist for commodities, and not for functionings").

37 Evangelii Gaudium, No. 53.
} 
imbalance is the result of ideologies which defend the absolute autonomy of the marketplace and financial speculation. Consequently, they reject the right of states, charged with vigilance for the common good, to exercise any form of control. A new tyranny is thus born ... ${ }^{38}$

The trope of the "throw away culture" serves for Francis as a kind of economic sibling to John Paul II's "culture of death." 39 By echoing his predecessor's language, Francis seems to signal that the modern market economy is rotten at its core in a way that calls into question the entire capitalist economic system as it actually operates today. Inverting John Paul II's critique of the "social welfare state," Francis criticizes social welfare efforts, not because of their bureaucratic inhumanity, but because they do not go nearly far enough. They merely paper over deeper structural problems within the market economy:

[S]ociety needs to be cured of a sickness which is weakening and frustrating it, and which can only lead to new crises. Welfare projects, which meet certain urgent needs, should be considered merely temporary responses. As long as the problems of the poor are not radically resolved by rejecting the absolute autonomy of markets and financial speculation and by attacking the structural causes of inequality, no solution will be found for the world's problems or, for that matter, to any problems. Inequality is the root of social ills. ${ }^{40}$

To summarize, then, in Francis's version of Catholic Social Teaching, we see a new attitude towards markets in a post-communist world. Like his predecessors, Francis takes a basic appreciation of private ownership and market transactions as a starting point. But from there he quickly shifts his attention to the shortcomings of the economy we have actually built on those twin pillars. Freed of the need to make a two-front battle against laissez faire capitalism and communism, he winds up with a position that is far more skeptical of modern capitalism than the views articulated by his predecessors. It is this deep-seated skepticism of property and markets as they actually function that guides his analysis of cap and trade.

\section{Francis's critique of Cap and Trade}

The entirety of Francis's discussion of market solutions to climate change is contained within just a few sentences in section 171 of Laudato Si. He says:

The strategy of buying and selling "carbon credits" can lead to a new form of speculation which would not help reduce the emission of polluting gases worldwide. This system seems to provide a quick and easy solution under the guise of a certain commitment to the environment, but in no way does it allow

38 Ibid. at 56.

${ }^{39}$ Evangelium Vitae, No. 12.

40 Evangelii Gaudium, No. 202. 
for the radical change which present circumstances require. Rather, it may simply become a ploy which permits maintaining the excessive consumption of some countries and sectors.

Within a short time of the encyclical's publication the passage became a lightning rod. Despite its somewhat confusing use of the term "carbon credits," most readers interpreted it as a swipe at all market-based approaches to reducing carbon emissions. Economists and environmentalists united to deplore the Pope's position. Robert Stavins, the director of Harvard's Environmental Economics Program typified this reaction when he wrote the following on the Huffington Post:

[Pope Francis's] unfortunate attack on the use of the market to address climate change is out of step with the thinking and the work of informed policy analysts and policy makers around the world, who recognize that we can do more, faster, and better with the use of market-based policy instruments - carbon taxes and/or cap-and-trade systems. ${ }^{41}$

Yale economist William Nordhaus concurred. "The encyclical," Nordhaus complained in an essay in the New York Review of Books, "overlooks the central part that markets, particularly market-based environmental policies such as carbon pricing, must play if countries are to make substantial progress in slowing global warming." 42 He went on to lament that, in Laudato Si, Francis

missed a unique opportunity to endorse one of the two crucial elements of an effective strategy for slowing climate change. He does indeed acknowledge the soundness of the science and the reality of global warming. It is unfortunate that he does not endorse a market-based solution, particularly carbon pricing, as the only practical policy tool we have to bend down the dangerous curves of climate change and the damages they cause. ${ }^{43}$

Some commentators have been broadly critical of market based environmental regulation because it commodifies environmental protection. ${ }^{44}$ This objection can

${ }^{41}$ R. Stavins, "The papal encyclical and climate change policy," The Huffington Post Blog, (Nov. 2, 2015) www.huffingtonpost.com/robert-stavins/the-papal-encyclicaland_b_8456424.html).

42 W. D. Nordhaus, "'Laudato Si': On care for our common home," The New York Review, (Oct. 8, 2015) (www.nybooks.com/articles/2015/10/08/pope-and-market/).

43 Ibid.

${ }^{44}$ See Vicki Bean, "Compensated siting proposals: is it time to pay attention?," Fordham Urb. L. J. 21 (1994), p. 824; Vicki Bean, "What's fairness got to do with it? Environmental justice and the siting of locally undesirable land uses," Cornell L. Rev. 78 (1993), p. 1041-41; S. Kelman, What price incentives?: economists and the environment, (Auburn House, 1981), p. 2 ("[T] he question of whether or not to use economic incentives in environmental policy is not simply a technical question, but is also an ideological, philosophical question ... and many noneconomist participants in the environmental debate tend to react to the issue in 
be framed in a number of different ways. First, it might mean that market-based regulations put a price on something (environmental protection) that is beyond price. This is a version of the commodification objection that Francis raises to markets in general, but it does not appear to be the crux of his objection to marketbased solutions to climate change.

Another version of this objection might focus on the impropriety of allocating environmental protection through markets in the context of inequality. In a recent book, Guido Calabresi discusses this objection in connection with what he calls "merit goods," goods that we are uncomfortable allocating through market mechanisms, particularly in a situation where purchasing power is distributed unequally. ${ }^{45}$ As Calabresi puts it, "[m]any in our society believe that certain goods (and bads) should be made available to (or imposed on) people in ways different fro the generality of goods and bads, that these goods (and bads) should be allocated in ways that do not depend primarily on the prevailing distribution of wealth." 46 This objection makes the most sense where market-based mechanisms are used to distribute pollution with highly localized effects. In those situations, wealthy communities can outbid poor communities to push offensive pollution elsewhere. ${ }^{47}$ But this objection is not particularly apt as applied to market-based climate policies. In the climate case, the objection is not that the poor will not be able to outbid the wealthy to avoid emissions. It is the opposite - that the poor will not be able to outbid the rich in order to emit. Moreover, carbon emissions do not generate particularly localized effects. ${ }^{48}$ They do not affect a local environment in the same way that other pollutants do. Market-based climate policies do not for the most part regulate local environmental quality as much as they regulate the ubiquitous activities that emit carbon. That is, they do not amount to policies that put a price on the entitlement to live in a healthy local environment.

A careful reading of the relevant language in the encyclical, however, makes clear that Francis is not making this sort of commodification argument. He does not seem rejecting market-based climate policy any more than he rejects markets generally. Or, more properly, he seems to be critical of market-based climate

ideological terms.”); F.B. Cross, “Natural resource damage valuation,” Vand. L. Rev. 42 (1989), p. 307 ("The lack of a functioning market in publicly held natural resources is a major impediment to reliance on market valuation. Furthermore, even if an effective market existed for the public utilization of natural resources, the market would undervalue the true use value of these resources.").

45 See G. Calabresi, The Future of Law and Economics, (Yale University Press, 2016) p. 41-45. 46 Ibid. at 42.

47 See A. Kaswan, "Environmental justice and environmental law," Fordham Envtl. L. Rev. 24 (2013), p. 161 ("Market-based programs like cap-and-trade are in fundamental tension with the environmental justice paradigm... The environmental justice community fears emission hot spots created by an industry or concentrated group of industries purchasing allowances rather than reducing emissions.").

48 Of course, they may accompany pollutants - such as particulates - that do. See D. A. Farber, "Pollution markets and social equity: analyzing the fairness of cap and trade," Ecology Law Quarterly, 39 (2012), p. 43. 
policies for precisely the same reasons (and to the same degree) that he is critical of markets.

This yoking of Francis's criticism of markets to his analysis of market-based climate solutions makes good conceptual sense. In many ways, the ubiquity of carbon emissions in the modern system of production and consumption makes climate change the environmental problem most closely aligned with Francis's "throw-away culture." On more than one occasion, Francis identifies the looming catastrophe of climate change with the prevailing "models of production and consumption." (LS 23, 26) As with that "throwaway culture," we can only combat climate change if we embrace "changes of lifestyle, production, and consumption." (LS 23)

When he turns to specific climate policies, Francis does not say that all "carbon credit" schemes must inexorably fail to reduce emissions or encourage speculation. He says that policies crafted along these lines "can" do so by simply replicating the injustices of global markets, creating "a new form of speculation" and facilitating continued "excessive consumption." Not all cap and trade schemes reinforce existing global inequalities, but poorly crafted policies might well have that effect.

In other words, in his critique of market based climate policies, Francis is simply observing that they may partake of the same pathologies already present in global markets and may under certain circumstances even exacerbate those pathologies. Because of the tight connection of carbon emissions to virtually every form of consumption (and, indeed, to economic activity of all sorts), reliance on market mechanisms to address climate change calls for extreme caution. That said, marketbased responses to climate change might be rendered entirely consistent with the moral framework of Laudato Si if they were crafted with sufficient sensitivity to Francis's broader critique of global markets.

A great deal depends on the details of the cap and trade program. For instance, a scheme in which carbon emission permits were simply auctioned off to the highest bidder would incorporate the economic inequality of the market system as a whole. ${ }^{49}$ The wealthy would be able to purchase permits to continue to emit (or, if it were cheaper reduce emissions). If reducing emissions were expensive, they could simply outbid the poor for the permits, and the poor would need to either pony up scarce resources to purchase permits or - if that were not feasible - cut back on their own emissions.

IV. Responding to Francis's critiques - what would a Franciscan Cap and Trade policy look like?

What would a market-based climate policy look like if it aimed to be responsive to Francis's concerns in Laudato Si? Francis himself offers some hints in the paragraphs prior to and following his critique of carbon trading. In the paragraph

${ }^{49}$ Cf. R. Posner, Economic Analysis of Law, 9th ed., (Wolters Kluwer, 2014), p. 15 ("If that distribution is unjust, the pattern of economic activities derived from it will not have a strong claim to be regarded as just either."). 
before, Francis argues that rich and poor countries are not equivalently situated with respect to responsibility for climate change:

Some strategies for lowering pollutant gas emissions call for the internationalization of environmental costs, which would risk imposing on countries with fewer resources burdensome commitments to reducing emissions comparable to those of the more industrialized countries. Imposing such measures penalizes those countries most in need of development. ... In this context, there is a need for common and differentiated responsibilities. As the bishops of Bolivia have stated, "the countries which have benefited from a high degree of industrialization, at the cost of enormous emissions of greenhouse gases, have a greater responsibility for providing a solution to the problems they have caused." (LS 170)

Two paragraphs later, Francis continues this theme of global inequality.

For poor countries, the priorities must be to eliminate extreme poverty and to promote the social development of their people. At the same time, they need to acknowledge the scandalous level of consumption in some privileged sectors of their population and to combat corruption more effectively. They are likewise bound to develop less polluting forms of energy production, but to do so they require the help of countries which have experienced great growth at the cost of the ongoing pollution of the planet. (LS 172)

In these passages, Francis is suggesting the need to take into account two intersecting axes of global inequality in crafting a just response to climate change. The first is inequality between the developing and the developed world. This inequality operates both on the level of responsibility for the problem of climate change (rooted in past inequality) and inequality in ability to absorb the costs of responding to climate change (rooted in present inequality).

As to the former, nations that experienced industrialization earlier in their history - for the most part in the global North - have contributed more to the buildup of greenhouse gases in the atmosphere than those whose industrialization has come more recently. According to one 2010 study, approximately $60 \%$ of the climate change impact as of today is due to the emissions of just six countries: the United States, Russia, the United Kingdom, Germany, France and Japan. ${ }^{50}$ Compounding this inequality in historic responsibility for greenhouse gas emissions is continuing economic inequality among nations, with earlier industrializing nations enjoying significant economic advantages over those who have industrialized more recently. The Pope sees both of these inequalities as relevant to the proper design of any response to climate change.

${ }^{50} \mathrm{~N}$. Hohne et al., "Contributions of individual countries' emissions to climate change and their uncertainty," Climatic Change, 106 (2011), 379. 
Both considerations can be coupled with market-based climate policies. One straightforward way to address these inequalities among nations is to incorporate them into discussions of the initial allocation of entitlements to emit greenhouse gases under a cap-and-trade system. Poorer countries and countries that bear less responsibility for existing accumulated greenhouse gases in the atmosphere (mostly the same countries) might be given higher emissions entitlements at the outset. In a global cap-and-trade system, these countries could sell their emissions entitlements to wealthier countries, using the money to upgrade their own technologies or to otherwise improve the standard of living of their residents. Making the initial allocations inalienable across national boundaries would also address Francis's concerns about wealth and historical responsibility, but it would prevent the kinds of wealth transfers that a global cap-and-trade system would facilitate.

In addition to this global distributive question, Francis expresses a concern about the distributive impact of climate policy within societies. That is, any policy that increases the cost of carbon emissions across the board is likely to have a regressive effect on the poorest members of a society. This is because the poor spend a greater percentage of their income on consumption than the wealthy. ${ }^{51}$ But the same mechanisms that address global inequality among nations can also address inequality of purchasing power within a particular society.

Allocating a nation's carbon budget to the least well off has the effect of redistributing property to the poor. Those who receive the initial allocation of carbon permits could use the entitlement themselves. Alternatively, they could limit their own emissions and sell the permit to those for whom it has more value. In either case, the permit gives them resources (a valuable entitlement to emit carbon) that they did not possess before.

Within a particular society, a cap-and-trade scheme might even become an affirmative vehicle to ameliorate economic inequalities. The state might, for example, auction off carbon credits but restrict the uses to which the revenue raised from those auctions could be put. (The same could be true of revenues generated from a carbon tax.) As long as the revenues were used to improve the well-being of the poorest members of the society, the climate policy would work to alleviate the kinds of market failures to which Francis objects. The revenue might be used for public education or for social welfare programs. It might also be used to engage in direct redistribution of money, such as a guaranteed minimum income or a negative income tax.

At the broadest level, climate policies designed to both make it more expensive to emit carbon and to concentrate the impact of those increases on the wealthier members of society (either within a nation state or globally) would seem to be entirely consistent with Francis's broader assessment of markets in Laudato Si.

\section{Conclusion}

${ }^{51}$ See S.E. Gaines and R.A. Westin, Taxation for Environmental Protection. 
Francis's approach to market based climate policies in Laudato $\mathrm{Si}$ is of a piece with his broader critique of modern capitalism. If market based systems are not sensitive to the distributive implications of the initial allocation of carbon emission entitlements, they will merely replicate or perhaps even reinforce the pathologies of the modern capitalist economy. But that does not mean they are categorically impermissible. It is possible to design such market-based approaches to climate policy with sensitivity to distributive justice. Doing so is entirely consistent with Francis's approach in Laudato Si. 